\title{
The nature of self-esteem and its relationship to anxiety and depression in adult
}

\section{$\underline{\text { acquired brain injury }}$}

\author{
Catherine Elaine Longworth ${ }^{1}$ \\ Joseph Deakins ${ }^{1,2,3}$ \\ David Rose ${ }^{2}$ \\ Fergus Gracey ${ }^{1,4}$
}

1. The Oliver Zangwill Centre for Neuropsychological Rehabilitation, Cambridgeshire Community Services (NHS) Trust, Ely Cambridgeshire, UK.

2. School of Psychology, University of Surrey, Guildford, UK.

3. Royal Hospital for Neuro-disability, West Hill, Putney, London, UK.

4. Department of Clinical Psychology and The Acquired Brain Injury Rehabilitation Affiliation, Faculty of Medicine and Health, University of East Anglia, Norwich, UK.

Correspondence concerning this article should be addressed to:

Dr Fergus Gracey, Department of Clinical Psychology, Faculty of Medicine and Health, University of East Anglia, Norwich Research Park, Norwich, NR4 7TJ, UK. Telephone: +44(0) 1603 592898. Email: f.gracey@uea.ac.uk

WORD COUNT: Abstract: 192 words. Manuscript: 8091 words. 
The nature of self-esteem and its relationship to Anxiety and Depression in adult

\title{
Acquired Brain Injury
}

\begin{abstract}
Acquired brain injury $(\mathrm{ABI})$ has a negative impact on self-esteem, which is in turn associated with mood disorders, maladaptive coping and reduced community participation. The aim of the current research was to explore self-esteem as a multidimensional construct and identify which factors are associated with symptoms of anxiety or depression. Eighty adults with ABI aged 17-56 years completed the Robson Self-Esteem Scale (RSES), of whom 65 also completed the Hospital Anxiety and Depression Scale. $57.5 \%$ of the sample had clinically low self-esteem. The RSES had good internal consistency $(\alpha=.89)$ and factor analysis identified four factors, which differed from those found previously in other populations. Multiple regression analysis revealed anxiety was differentially predicted by "Self-Worth" and "SelfEfficacy" $\left(R^{2}=.44, F(4,58)=9, p<.001\right)$ and depression by "Self-Regard" $\left(R^{2}=.38\right.$, $F(4,58)=9, p<.001)$. A fourth factor, "Confidence", did not predict depression or anxiety. In conclusion, the RSES is a reliable measure of self-esteem after ABI. Selfesteem after $\mathrm{ABI}$ is multidimensional and differs in structure from self-esteem in the general population. A multidimensional model of self-esteem may be helpful in development of transdiagnostic cognitive behavioural accounts of adjustment.
\end{abstract}

KEYWORDS: brain injury, self-esteem, depression, anxiety, cognitive therapy patient group. 


\section{Introduction}

Acquired brain injury (ABI) refers to any sudden onset injury to the brain sustained after birth and a period of normal development. The global incidence of traumatic brain injury (TBI) is estimated at 235 per 100,000 people per year (Corrigan et al., 2010) and 160 to 350 per 100,000 people per year for strokes (Zhang, Chapman, Plested, Jackson, \& Purroy, 2012). For these people, ABI can result in profound changes to many aspects of life, including physical, sensory and perceptual abilities, cognition, communication and ability to regulate mood, any one of which may affect their ability to participate in society (perform activities associated with daily living, family life, work or leisure; Hoofien, Gilboa, Vakil, \& Donovick, (2001). The emotional and psychiatric sequelae of $\mathrm{ABI}$ are significant and affect the individual as well as families and carers (Oddy and Herbert, 2003). Estimates of depression after TBI range from $14 \%$ to $77 \%$ (Whelan-Goodinson, Ponsford, \& Schönberger, 2008) and are commonly cited at 33\% after stroke (Hackett, Yapa, Parag, \& Anderson, 2005). Suicide rates increase approximately four times after TBI and double after stroke (Teasdale \& Engberg, 2001). It has been estimated that $38 \%$ of TBI survivors will experience an anxiety disorder (Whelan-Goodinson et al., 2008).

These changes often affect how survivors view themselves, or their self-concept (Cantor, Ashman, Schwartz, Gordon, Hibbard, Brown et al., 2005; Carroll \& Coetzer, 2011; Ellis-Hill \& Horn, 2000; Gracey, Palmer, Rous, Psaila, Shaw et al., 2008; Gutman \& Napier-Klemic, 1996; Nochi, 1998, 2000; Tyerman \& Humphrey, 1984; Yeates, Henwood, Gracey, \& Evans, 2007) defined as “the sum of an individual's beliefs and knowledge about his/her personal attributes and qualities" (Mann, 
Hosman, Schaalma, \& de Vries, 2004) and their worth, or self-esteem (Brinkmann \& Hoskins, 1979; Cooper-Evans, Alderman, Knight, \& Oddy, 2008; Curran, Ponsford, \& Crowe, 2000; Wright \& Telford, 1996) defined as "the evaluative and affective dimension of the self-concept" (Mann et al., 2004) or in terms of belief in both one's ability and self-worth (Branden, 2001). Survivors of ABI rate their self-esteem after injury as lower than before injury (Cooper-Evans et al., 2008). Low self-esteem has been associated with negative perceptions of body image after stroke or TBI (Howes, Edwards, \& Benton, 2005a, 2005b; Keppel \& Crowe, 2000) less severe cognitive impairment and intact self-awareness (Cooper-Evans et al., 2008), and pre-post injury self-discrepancy (Carroll \& Coetzer, 2011) but not with age at injury or severity of ABI (Garske \& Thomas, 1992). As in the general population, significant associations have been reported between low self-esteem and both anxiety and depression following ABI (Cooper-Evans et al., 2008; Curran et al., 2000; Vickery, 2006; Vickery, Sepehri, Evans, \& Jabeen, 2009; Garske \& Thomas, 1992; Howes et al., 2005a, 2005b). Rates of co-morbidity of anxiety and depression appear to be elevated amongst people post TBI (Jorge \& Starkstein, 2005), inviting the need for an integrated, transdiagnostic model of post-injury psychopathology (Gracey, Evans, \& Malley, 2009; Gracey, Ford, \& Psaila, 2015; Jorge \& Starkstein, 2005; Shields, Ownsworth, O'Donovan \& Fleming, 2015;). It has been suggested that ABI survivors with "diminished self-concept" may not participate as fully in rehabilitation or community activities due to fear of failure and further threat to self-esteem (Vickery, Gontkovsky, Wallace, \& Caroselli, 2006). In keeping with this Riley, Dennis, \& Powell (2010) found that low self-esteem was a moderator of the relationship between threat appraisal and anxious avoidance. 
Fennell's (Fennell, 1997; 1998) cognitive behavioural model of low self-esteem suggests that negative experiences of interpersonal relationships, particularly in early life, result in global negative self-evaluation and setting high personal standards for measuring self-worth. The model predicts that low self-esteem results either in anxiety, when it is feared that personal standards will not be met or depression when it is confirmed that personal standards have not been met. The relationship between specific patterns of cognition arising from underlying low self-esteem and resultant anxiety or depression provides a specific target for cognitive-behavioural intervention. In line with these predictions low self-esteem is associated with anxiety (Beck, Brown, Steer, Kuyken, \& Grisham, 2001), depression (Brown, Andrews, Bifulco, \& Veiel, 1990; Rice, Ashby, \& Slaney, 1998), remitted unipolar depression (Daskalopoulou et al., 2002) and suicidality (Dori \& Overholser, 1999), suggesting that it is associated with psychopathology in general. In light of Fennell's (1997, 1998) model of low self-esteem the association between ABI and low self-esteem might indicate that $\mathrm{ABI}$ challenges the ability to meet the standards people set for their own self-worth (as a result of acquired deficits and negative evaluation of these), which is likely to result in anxiety and or depression. As a potentially viable transdiagnostic target for clinical research and intervention development following ABI, robust conceptualisation and measurement of self-esteem in this population is required.

To date most research into self-esteem following ABI has measured self-esteem using the Rosenberg Self-Esteem Questionnaire (Rosenberg, 1965). This has been considered the "gold standard" of self- esteem measurement (Hatcher \& Hall, 2009; p. 71) and has good reliability and validity in both the general population (Gray-Little, 
Williams, \& Hancock, 1997) and in ABI (Anson \& Jennie Ponsford, 2006; Curran et al., 2000; Garske \& Thomas, 1992; Howes et al., 2005a, 2005b; Keppel \& Crowe, 2000). It is a short, 10-item scale that measures self-esteem as a unidimensional construct. However, some argue that self-esteem is better conceptualised as multidimensional (Vallerand, Pelletier, \& Gagné, 1991) identifying aspects pertinent to both ability and worth (Branden, 2001). To measure the multidimensional nature of self-esteem Robson (1989) developed the Robson Self-Esteem Scale (RSES). Good reliability and validity has been reported with a psychiatric cohort (Robson, 1989) and a non-psychiatric cohort (Addeo, Greene, \& Geisser, 1994; Robson, 1989) and the scale has been adopted by CBT research on self-esteem (McManus, Waite, \& Shafran, 2009) in order to measure the specific contributions of dimensions of self-esteem to anxiety and depression. Factor analysis has supported the multidimensional interpretation of the RSES, although different factor structures have been proposed, with Robson finding five factors labelled: Attractiveness; Contentment, Worthiness, Significance; Autonomous Self-Regard; Self-Efficacy; and Value of Existence (Robson, 2002; personal communication, June, 5, 2009) and Addeo and colleagues finding three factors, labelled: Self-Deprecation, Attractiveness and SelfRespect/Confidence (Addeo et al., 1994). There are no published studies of which we are aware that have used the RSES with an ABI sample.

The aim of the current study was to develop a detailed understanding of dimensions of self-esteem in ABI in order to contribute to future design and evaluation of psychological interventions. The first aim was to assess the psychometric properties of the RSES so that its use in mental health and CBT research can be extended to include people with ABI. Our second aim was to investigate whether self-esteem is 
best conceptualised as multi-dimensional rather than uni-dimensional after $\mathrm{ABI}$ and if so, whether the factor structure supports the factors identified by Robson or by Addeo in the general population. Our third aim was to investigate whether specific factors of self-esteem are more strongly linked to measures of anxiety and depression than other factors, as predicted by Fennell (1997, 1998). Given previous research linking negative perception of body image after $\mathrm{ABI}$ to low self-esteem we further hypothesized that one factor of self-esteem after ABI would be attractiveness, as found previously by Robson in the non brain-injured population, and that this would be negatively associated with depression.

\section{Method}

\section{Design}

A within-subjects correlational design was used in order to conduct confirmatory and exploratory factor analyses, then to predict anxiety and depression from the factors identified.

\section{Participants}

The study employed secondary analysis of anonymised, routinely collected, clinical data. The data were collated from individuals who were consecutive accepted referrals to a neuropsychological rehabilitation service providing comprehensive day programme rehabilitation (as defined by Trexler, 2000; and Wilson, Malley, Gracey, Bateman \& Evans, 2009) for people with enduring problems with cognition, communication, emotional and social adjustment following ABI that interfere with relationships, social roles and everyday activities. Assessment for rehabilitation includes routine measurement of self-esteem, anxiety and depression. Inclusion in the 
study followed service inclusion and exclusion criteria: age 16 or over, evidence of an acquired brain injury (from medical records), more than 9 months post-injury, no current severe and enduring psychiatric disorder or substance misuse disorder, no severe behavioural disturbance, no gross language impairment, sufficient cognitive ability to consent to and engage in neuropsychological rehabilitation. All accepted referrals had completed a RSES.

\section{Measures}

The Robson Self-Esteem Scale (RSES)

Robson Self-Esteem Scale (Robson, 1989) was used as a multi-dimensional measure of self-esteem. It is a 30 item, self-report questionnaire measure that takes about ten minutes to complete. Each item consists of a statement relating to self-esteem (e.g. "I'm easy to like") and respondents indicate the degree to which they agree with the statement on an 8-point Likert scale from 0 (completely disagree) to 7 (completely agree). It has demonstrated good internal consistency, split-half reliability, test-retest reliability and good convergent validity with the Rosenberg Self-Esteem Questionnaire in healthy volunteers (Robson, 1989; Addeo et al. 1994). Robson (1989) reported healthy control means of $137(S D=20.1)$ and $140(S D=19.8)$ recommending a mean of 140 and standard deviation of 20 is used in routine clinical practice. Psychiatric means of 100-108 $(S D=24-25)$ have been reported (Robson, 1989).

The Hospital Anxiety and Depression Scale (HADS).

The HADS (Zigmond \& Snaith, 1983) was used to measure depression and anxiety. It is a 10 -minute, 14 item, self-report questionnaire designed for measuring symptoms 
of anxiety and depression in medical patients. Each item consists of a statement about a symptom (e.g. "I feel tense or wound up") and respondents indicate the degree to which they experienced that symptom over the past week on 4-point anchored scales. Scores are summed within anxiety (HADS-A, 7 items) and depression (HADS-D, 7 items) subscales and range from 0-21, with cut-off points at 8 (mild), 11 (moderate) and 16 (severe). It has good internal consistency (Cronbach's alphas: .89 HADS-A, .86 HADS-D) (Olssøn, Mykletun, \& Dahl, 2005) and good concurrent validity with other measures of anxiety and depression (Bjelland, Dahl, Haug, \& Neckelmann, 2002). The HADS has been found to be a valid tool for the assessment of anxiety and depression following TBI (Whelan-Goodinson, Ponsford, \& Schönberger, 2009). The 2-factor structure of the HADS has been found to fit across a wide range of disorders (Norton, Cosco, Doyle, Done \& Sacker, 2012) and for both ABI and TBI respectively (Dawkins, Cloherty, Gracey, \& Evans, 2006; Schönberger \& Ponsford, 2010). Although all accepted referrals were assessed for anxiety and depression, the HADS was not always completed as some individuals completed other depression or anxiety measures, or no formal measures, depending on clinical need and assessment priorities.

The Speed and Capacity of Language Processing (SCOLP)

The SCOLP (Baddeley, Emslie and Nimmo-Smith, 1992) is a neuropsychological assessment that comprises 2 tasks. The timed 'Speed of Comprehension' subtest evaluates speed of language processing (considered vulnerable to the effects of brain injury), the 'Spot the Word' subtest is an assessment of verbal knowledge (considered indicative of general intellectual functioning, relatively less affected by brain injury). The SCOLP was administered as part of the routine assessment battery, and the Spot 
the Word test score collated for analysis here to provide an indication of pre-injury intellectual functioning.

\section{Procedure}

The chair of the local health services research ethics committee gave approval for the secondary analysis of this routinely and previously collected, anonymised clinical data. As such the study was defined as service evaluation rather than research in accordance with UK Health Research Authority guidelines (REF). Ethical approval for the protocol was also sought and provided by the University of Surrey research ethics committee. The data for this study were collected as part of routine clinical assessment of consecutive accepted referrals to the rehabilitation service. Consent for potential use of anonymised data for service evaluation was provided alongside consent for assessment. The detailed clinical assessment in which RSES and HADS were administered occurred following an initial clinical assessment, which ascertained whether the person met inclusion and exclusion criteria for the service. RSES and HADS measures were given to participants to complete, which they did so independently, or with support from an appropriately trained graduate psychology practitioner if required. Data analysis was performed using SPSS versions 16 and 17.

\section{Results}

\section{Participant characteristics}

Eighty participants were assessed, 54 (67.5\%) of whom sustained TBI (severe $=39$ $(79.6 \%) ;$ moderate $=4(8.2 \%) ;$ mild $=6(12.2 \%)$, based on the Mayo classification system, including Glasgow Coma Scale, duration of coma or post traumatic amnesia, (Malec, Brown, Leibsen, Flaada et al, 2007). The other causes of injury were stroke (n 
$=18,22.5 \%)$, encephalitis $(n=3,3.8 \%)$, hypoxia $(n=2,2.5 \%)$, meningitis $(n=1$, $1.3 \%)$ and other $(\mathrm{n}=2,2.5 \%)$. The average time since injury was 47.5 months $(S D=$ 48.21) with the range varying from 10 to 229 months. 54 (67.5\%) participants were male and $26(32.5 \%)$ were female. They were aged between 17 and 56 years $(M=$ 35.55, $S D=10.83$ ), and estimated pre-morbid intellectual functioning (SCOLP Spotthe-Word scaled score) was average $($ mean $=9.54 ; S D=3.1 ; \mathrm{n}=69)$.

\section{Data Preparation}

80 participants completed the RSES and 65 also completed the HADS. Prior to analysis missing RSES data (1\%) were replaced with the midpoint of the scale (3.5) and negatively worded items were recoded (reversed) so that positive scores indicate good self-esteem in keeping with the scoring guidance.

\section{Global Self-Esteem}

The mean global RSES score was $115.71(S D=30.37)$. Low self-esteem was common with over half the sample $(\mathrm{N}=46,57.5 \%)$ scoring one standard deviation below the healthy control mean (i.e. less than 120$)$, of whom $26 \%(\mathrm{~N}=21)$ scored two standard deviations below the mean. It was not possible to analyse data to compare levels of self-esteem of participants with different severities of with TBI due to the small subgroup sizes (mild TBI $n=6$; moderate TBI $n=4$ ). There was no statistically significant difference in global self-esteem between men $(M=117.64, S D$ $=31.79)$ and women $(M=111.7, S D=27.34)(t(78)=0.82, p=.42)$ and no significant correlations between self-esteem and age $(r(78)=.06, p=.6)$, time since injury $(r h o(78)=-.16, p=.15)$ or pre-injury intellectual functioning as measured by the $\operatorname{SCOLP}(r(67)=.07, p=.57)$. 


\section{Anxiety and Depression}

The mean HADS score for anxiety was $7.31(S D=4.66) .36(55 \%)$ participants scored in the normal range for anxiety, $13(20 \%)$ as mildly anxious, $13(20 \%)$ as moderately anxious and $3(5 \%)$ as severely anxious. The mean HADS score for depression was $8.25(S D=5.08) .30(46 \%)$ participants scored in the normal range for depression, $13(20 \%)$ as mildly depressed, 17 (26\%) as moderately depressed and $5(8 \%)$ as severely depressed.

\section{Associations between Global Self-Esteem and Anxiety and Depression}

There were strong negative correlations between global self-esteem and both anxiety $(r(63)=-.64, p<.001)$ and depression $(r(63)=-.61, p<.001)$ indicating that participants with lower self-esteem endorse higher levels of symptoms of depression and anxiety than those with higher self-esteem.

\section{Internal Consistency of the RSES}

Four questions were removed due to large numbers of negative inter-item correlations: 6 "I can never seem to achieve anything worthwhile", 12 "I am a reliable person", 22 "There's a lot of truth in the saying: what will be, will be" and 25 "It's pretty tough to be me". With these items removed Cronbach's $\alpha(.89)$ and Guttmann split half reliability (.75) indicated good internal consistency. No significant improvements of the Cronbach's $\alpha$ were made through deleting any more of the remaining 26 items.

\section{Confirmatory factor analysis}


The Kaiser-Meyer-Olkin (KMO) measure of sampling adequacy was .79 and Bartlett's Test of Sphericity was significant $(p<.001)$ indicating that data from the remaining 26 items were appropriate for factor analysis. There were no large interitem correlations and the Haitovsky test was significant $(p<.001)$ indicating that multicollinearity was not problematic.

To test whether self-esteem in ABI as measured by the RSES has a similar structure to that reported for the general population, Addeo et al's (1994) three and Robson's (2009) five factor models for the RSES were tested using a Maximum Likelihood Factor Analysis (MLFA) with a Direct Oblimin (oblique) rotation and mean substitution of missing values. The Goodness-of-Fit score for a three-factor model was significant indicating significant differences between the observed data and that predicted by a three-factor solution $(\chi 2(250)=288.24, p=.05)$. This suggests that in ABI, contrary to the findings of Addeo et al. (1994) for healthy college students, a three-factor model was not suitable.

The Goodness-of-Fit score for a five-factor model was non-significant $\left(\chi^{2}(205)=\right.$ $197.78, p=.63$ ). Factor loadings below 0.4 were suppressed (Field, 2013) although two items only marginally below cut off (.39) were also considered. The factors corresponded only in part with Robson's original five factors. The first factor shared four items (2, 9, 15 and 30) with Robson's 'Attractiveness' factor. The second factor contained three items that corresponded to Robson's factor of 'Self-Efficacy' (16, 18 and 26). However, the third and fourth factors did not correspond with any of Robson's factors and the fifth factor contained only two items, making it unsuitable to label. Nine items did not load onto any of the factors, and one item was considered a 
Heywood case (item 18 had a communality greater than 1.0). This indicates problems with the interpretation of Robson's proposed five-factor model.

\section{Exploratory factor analysis}

Principle Axis Factoring (PAF) with a Direct Oblimin (oblique) rotation and means substitution was used to test a four-factor model, which would be consistent with the scree plot. The factor structure obtained through the PAF was clear and easy to interpret. Only four items failed to load $(1,13,21, \& 23)$ and no Haywood case was present, although two items still loaded onto two factors (8 and 29). After careful consideration items less then 0.39 were suppressed as two items were close to the normal 0.4 cut-off point (Field, 2013). The factor correlation matrix was explored (Table 1). The presence of correlations between factors 1, 2 and 3 with a medium effect size (Cohen, 1988) together with the inter-item correlations suggests possible presence of a higher order factor (Addeo et al., 1994) considered to be global selfesteem by Robson (1989). However, as none of the correlations were significant, the factors can be considered distinct dimensions of self-esteem, in keeping with (Robson, 1989). Together the 4 factors accounted for $50 \%$ of the variance.

Table 1 about here

The items corresponding to each factor are given in table 2. The first factor was labelled "Self-Worth" and consisted of nine questions (4, 5, 7, 8, 11, 17, 20, 27 and 28) four of which corresponded with Robson's 'Value of Existence' (4, 7, 11, and 20) factor and three with Robson's factor of 'Contentment worthiness and significance" $(5,17$, and 27). This factor had good internal consistency (Cronbach's alpha $=.82)$. 
The second factor, labelled "Self-Regard", consisted of eight items (2, 3, 9, 10, 15, 24, 29 and 30) with four each from Robson's “Attractiveness” $(2,9,15,30)$ and “Autonomous Self-Regard” (3, 10, 24, 29) factors. This factor had good internal consistency (Cronbach's alpha = .86). The third factor, labelled "Self-Efficacy", contained four items (16, 18, 26 and 29), with three from Robson's "Self-Efficacy" factor $(16,18,26)$ and one from his "Autonomous self-regard" (29) factor, this item also loading on "Self-Regard". This factor had acceptable internal consistency (Cronbach's alpha $=.72)$. The fourth factor, labelled "Confidence and Determinism", consisted of three items $(8,14, \& 19)$, one of which corresponded with an item from Robson's factor "Contentment worthiness and significance" (19) and another loaded on both this factor and "Self-Worth" (8). Two items (8 and 14) concerned the notion of luck and locus of control, although could be considered ambiguous. This factor had questionable internal consistency (Cronbach's alpha $=.6$ ).

Table 2 about here

\section{Self-Esteem, Mood and Anxiety}

All four factors had moderate to strong negative correlations with levels of anxiety symptoms. Self-Worth, Self-Regard and Self-Efficacy, but not Confidence and Determinism, also showed moderate to strong negative correlations with levels of depression symptoms (see Table 3 ).

Table 3 about here

Given the absence of correlations between gender, age, time since injury or pre- 
morbid estimated intellectual functioning, the RSES factors were entered as predictors of anxiety and depression in simultaneous multiple regression models (see Table 2). The four factors differentially predicted levels of depression and anxiety symptoms. The results show that only Self-Regard predicted HADS depression, accounting for $38 \%$ of variance $\left(\mathrm{R}^{2}=0.38, F(4,58)=9.00, \mathrm{p}<0.001\right)$ such that lower self-regard was associated with greater depression $(\beta=-0.38, \mathrm{p}=0.01)$. A two factor model comprising Self-Worth $(\beta=-0.39, \mathrm{p}<0.01)$ and Self-Efficacy $(\beta=-0.30, \mathrm{p}<0.05)$ significantly predicted HADS anxiety accounting for $44 \%$ of the variance $\left(\mathrm{R}^{2}=0.44\right.$, $F(4,58)=11.26, \mathrm{p}<0.001)$.

Table 4 about here

\section{Discussion}

This study is the first to evaluate systematically a multidimensional conceptualisation of self-esteem following brain injury and associations between dimensions of selfesteem and symptoms of anxiety and depression, utilising a specific multidimensional measure of self-esteem, the RSES. The first aim was to assess the psychometric properties of this measure. We found the RSES to be a reliable measure of self-esteem in ABI. The psychometric properties of the RSES were improved by removal of 4 items, suggesting a revised 26-item version of the measure might be more appropriate for people with ABI. Although construct validity of the RSES was not explored through comparison of scores on the Rosenberg, the overall finding of high levels of low self-esteem and association of low self-esteem with anxiety and depression is in keeping with previous findings utilizing the Rosenberg (e.g. Cooper-Evans et al, 2008). 
The second aim was to investigate whether a multi-dimensional conceptualisation of self-esteem is warranted, and if so, whether the factor structure supports the factors identified by Robson (2002) or by Addeo et al (1994) in the non-ABI population. Four dimensions of self-esteem after ABI were identified and were labelled, Self-Worth, Self-Regard, Self-Efficacy and Confidence and Determinism. The internal consistency of the Confidence dimension was questionable, but the other dimensions had acceptable to good internal consistency. The factor structure differed from that previously identified in non-ABI samples, suggesting those with ABI may have different concerns regarding their self-concept than those without ABI. The findings are consistent with Robson's (1989) notion of a multidimensional self-esteem construct, but also indicate the presence of a higher-order construct, as suggested by Addeo et al (1994). This suggests that whilst measures such as the Rosenberg are valid and useful for assessment of self-esteem as a uni-dimensional construct, clinical assessment using a multi-dimensional measure may be informative for clinical formulation of the components of self-esteem impacting emotional functioning in ABI. However, the variation in the nature of factors identified across factor-analytic studies with psychiatric, healthy and now brain injured participants, suggests differences in the components of self-esteem depending on the circumstances or concerns that may be particular to a clinical group. Therefore we could not recommend on the basis of this study that the factor structure here identified should be readily applied to different ABI patient groups. A prospective study with a larger random sample would be required.

Our third aim was to investigate whether specific dimensions of self-esteem are 
correlated more strongly with anxiety or depression as predicted by Fennell's (1997, 1998) cognitive model. Consistent with previous research, and employing Robson's cut-off for low global self-esteem, the current sample of ABI survivors had a relatively high rate of low self-esteem associated with high levels of symptoms of depression and anxiety. Specifically, Self-Worth and Self-Efficacy predicted levels of anxiety symptoms after ABI. The items relating to Self-Worth included those about achievement ("I can never seem to achieve anything worthwhile"), emotional responses to negative evaluation by others ("When people criticise me, I often feel helpless and second-rate", "I often feel humiliated") and self-to-self relating ("I don't care what happens to me"). The factor overlaps with items from Robson's factors "Contentment, worthiness and significance" and "Value of Existence". This suggests that for the current ABI sample beliefs about abilities, feelings about evaluation by others and feelings towards oneself are more highly interrelated than in Robson's sample of people from the general population. One possible interpretation of this is that beliefs about societal evaluation of achievements and ability after ABI are linked to perceived stigma or negative judgment by others, as identified by Jones et al. (2011). This is also consistent with Fennell's (1997) cognitive-behavioural model of low self-esteem, which suggests that low self-esteem causes anxiety when it is feared that personal standards for worthiness may not be met.

The other factor predicting levels of anxiety symptoms, Self-Efficacy, contains a subset of items from Robson's factor "Self Efficacy" and one item from the factor “Autonomous self-regard” (“I can like myself even when others don't”). Self-Efficacy has been defined as “the belief in one's capabilities to organize and execute the courses of action required to manage prospective situations" (Bandura, 1995; p. 2) 
and the items in this factor relate to withstanding, overcoming or persisting despite difficulties (e.g. "I can usually make up my mind and stick to it", "if a task is difficult, that just makes me all the more determined"). Self-efficacy has been associated with psychosocial outcomes following ABI (Cicerone \& Azulay, 2007; Wood \& Rutterford, 2006) as well as responsiveness to intervention in neuropsychological rehabilitation (Cicerone et al., 2008). Self-efficacy has emerged as a significant predictor of participation, quality of life and emotional functioning (Brands, Kohler, Stapert, Wade, \& van Heugten, 2014); Cicerone \& Azulay, 2007; (Tielemans, Schepers, Visser-Meily, Post, \& van Heugten, 2015); Wood \& Rutterford, 2006), although effects on emotional functioning may be via the mediating factor of proactive coping (Tielemans et al., 2015).

The finding is also consistent with Fennell's $(1997 ; 1998)$ model of low self-esteem if it is assumed that anxiety arises from perceived threat to the ability to cope with challenges, including negative emotions, in line with personal standards. The multiple regression findings suggest that fear of negative evaluation due to acquired impairments (low Self-Worth) and low perceived ability to overcome or withstand difficulties (low Self-Efficacy) are particularly associated with levels of anxiety symptoms after ABI. These could therefore be useful targets for therapeutic interventions as highlighted by (Gracey et al., 2015).

"Self-Regard" was the dimension of self-esteem that predicted levels of depression symptoms after ABI. The items making up this factor of the RSES overlap with those from Robson's factors “Attractiveness” and "Autonomous Self Regard”. It had been predicted that attractiveness might be one factor of self-esteem after ABI given 
previous research linking negative perception of body image after ABI to low selfesteem (Howes et al., 2005a, 2005b; Keppel \& Crowe, 2000). There is some support for this hypothesis from the overlap between our Self-Regard factor and Robson's Attractiveness factor. However, the overlapping items include only one item specifically mentioning physical image ("Most people find me reasonably attractive") and the other RSES item that mentions physical image ("I look awful these days") did not feature in any of the four factors identified in this study. Given the items in the factor Self-Regard, it appears that for the current ABI sample beliefs about relationships with others ("Those who know me well are fond of me") rather than beliefs specifically about body image, may be related to the valency of the self-to-self relationship ("I'm glad I'm who I am"), whereas in the general population these can function as distinct dimensions of self-esteem. This suggests that after ABI self-to-self relating is likely to be influenced by the quality of relationships with others to a greater degree than in the general population. This might go part of the way to explaining the vulnerability of ABI survivors to depression, given evidence of the social isolation they and their families suffer (Kinsella, Ford, \& Moran, 1989) that increases over time (Brooks, McKinlay, Symington, Beattie, \& Campsie, 1987). The quality of relationships may become more important at the very time that access to relationships becomes increasingly difficult.

The multiple regression findings suggest that perceptions of oneself as unlikeable after ABI are particularly associated with level of depression symptoms, consistent with Malec, Brown, Moessner, Stump, \& Monahan (2010) and may be a useful key target for therapeutic interventions. Fennell's model suggests that low self-esteem results in depression when it is perceived that personal standards have not been met or 
cannot be met. The results of the current study suggest that, for people with ABI, failure to live up to an internal standard of 'Self-Regard' may be associated with symptoms of depression. A promising line of enquiry in approaches for addressing self-criticism and shame associated with low self-esteem in the general population as well as post ABI (Ashworth, Gracey \& Gilbert, 2011; Ashworth, 2014) is emerging in research into self-compassion and the potential for specific compassion-focused techniques to improve self-esteem/depression.

The subgroup sample size was too small to analyse differences in self-esteem between people with mild, moderate or severe TBI. Inconsistent findings have emerged from previous research (Garske \& Thomas, 1992; Cooper-Evans et al., 2008). The use of a multidimensional approach to measurement of self-esteem might help disambiguate evidence about the nature of the self-esteem difference between people with moderate and severe brain injuries, as different types of consequence might impact individuals differently. In the current study the possibility that relationships between self-esteem, anxiety and depression might differ between different aetiologies of brain injury was not investigated. Further research into dimensions of self-esteem, and relationships between other constructs found to be associated with poor outcome after ABI such as self discrepancy (Cantor et al, 2005; Carroll \& Coetzer, 2011; Ellis-Hill \& Horn, 2000; Gracey et al., 2008), coping style (Anson \& Ponsford, 2006; Curran et al., 2000; Tielmans et al 2014; Brands et al, 2014), self-awareness (Carroll \& Coetzer, 2011; Cooper-Evans et al, 2008) and threat appraisal (Riley, Brennan, \& Powell, 2004; Riley et al., 2010) are also warranted to contribute to the development of a transdiagnostic framework for psychological assessment and intervention following ABI. It may be that the concept of global self-esteem is less clinically useful and less 
theoretically robust than specific constructs such as self-efficacy, or other specific aspects of experience of self, however this is an empirical question that requires further investigation.

This study has a relatively large sample compared to previous research on self-esteem after ABI. One of the limitations of the study, however, is that the sampling was nonrandom and covers multiple aetiologies, and not all participants completed the HADS. Measures were completed during assessment for a comprehensive neuropsychological rehabilitation day programme. The programme is specifically aimed at ABI survivors with complex and interacting difficulties a year or more following ABI. Many clients on the programme have cognitive, affective, communication and functional difficulties, with fewer clients with physical difficulties or aphasia. It is unclear to what extent the findings generalise to ABI survivors with fewer or less complex difficulties (not seeking intervention from specialist rehabilitation services), physical disability, aphasia or aetiologies which are less well represented in this sample, such as people with encephalitis or cerebral anoxia. Nevertheless, this study is part of a growing body of research reporting low self-esteem following different types and levels of ABI. A second limitation of the study is that it does not address the cognitive or functional status of the participants and therefore we are unable to assess the extent to which self-esteem relates to these aspects of ABI. Also, as with most research in this field, the current study relied on self-report measures of self-esteem and mood, which may be vulnerable to reduced reliability and validity in the context of acquired cognitive and communication difficulties. However, Cooper-Evans et al. (2008) have established that self-reported self-esteem is reliable even for people with severe TBI. The current study also did not attend to the level of self-awareness of participants, 
which has previously emerged as an important correlate of self-esteem (Carroll \& Coetzer, 2011; Cooper-Evans et al, 2008). Finally, the finding of associations between dimensions of self-esteem and mood after ABI does not allow us to draw conclusions about the direction of causality, for which prospective longitudinal studies are required.

\section{Conclusions}

In conclusion, the study suggests the RSES is a reliable multidimensional measure of self-esteem after ABI, provides evidence that self-esteem after ABI is multidimensional and differs in structure from self-esteem in the general population. The clinical importance of identifying low self-esteem as a transdiagnostic variable following $\mathrm{ABI}$ is highlighted by its association with depression and anxiety. In clinical practice, assessment of psychological factors such as self-efficacy that may contribute to global self-esteem may be helpful in contributing to clinical formulation and intervention planning. Our results suggest that key targets for cognitive intervention with $\mathrm{ABI}$ survivors are negative social evaluations such as perceptions of being unlikeable after ABI, the perceived likelihood of negative evaluation due to acquired impairments and low perceived self-efficacy to withstand difficulties. Further research is required to replicate and extend the finding that self-esteem after $\mathrm{ABI}$ is multidimensional and to design and evaluate targeted therapeutic interventions to increase self-esteem after ABI. 


\section{Acknowledgements}

This paper presents independent research supported by the National Institute for Health Research (NIHR) Collaborations for Leadership in Applied Health Research and Care (CLAHRC) for Cambridgeshire and Peterborough and NIHR Flexibility and Sustainability Funding provided by Cambridgeshire Primary Care Trust. The views expressed are those of the author(s) and not necessarily those of the National Health Service, the NIHR or the Department of Health.

The authors declare no conflicts of interest. 


\section{REFERENCES}

Addeo, R.R., Greene, A.F., \& Geisser, M.E. (1994). Construct validity of the Robson self-esteem questionnaire in a college sample. Educational and Psychological Measurement, 54(2), 439-446. doi: 10.1177/0013164494054002018

Anson, K., \& Ponsford, J. (2006). Coping and emotional adjustment following traumatic brain injury. Journal of Head Trauma Rehabilitation, 21(3), 248259.

Anson, K., \& Ponsford, J. (2006). Evaluation of a coping skills group following traumatic brain injury. Brain Injury, 20(2), 167-178. doi:

$10.1080 / 02699050500442956$

Ashworth, F., et al. (2011). "Compassion Focused Therapy After Traumatic Brain Injury: Theoretical Foundations and a Case Illustration." Brain Impairment, 12(2): 128-139.

Ashworth, F. (2014). "Soothing the Injured Brain with a Compassionate Mind: Building the Case for Compassion Focused Therapy following Acquired Brain Injury." Neuro-Disability and Psychotherapy, 2(1-2): 41-79.

Baddeley, A.D., Emslie, H. \& Nimmo-Smith, I. (1992). The Speed and Capacity of Language Processing (SCOLP) Test. Bury St Edmunds, Suffolk: Thames Valley Test Company.

Bandura, A. (1995). Self-efficacy in changing societies: Cambridge University Press.

Beck, A.T., Brown, G.K., Steer, R.A., Kuyken, W., \& Grisham, J. (2001). Psychometric properties of the Beck self-esteem scales. Behaviour Research and Therapy, 39(1), 115-124. doi: http://dx.doi.org/10.1016/S00057967(00)00028-0

Bjelland, I., Dahl, A.A., Haug, T.T., \& Neckelmann, D. (2002). The validity of the 
Hospital Anxiety and Depression Scale. An updated literature review. Journal of Psychosometric Research, 52(2), 69-77.

Branden, N. (2001). The psychology of self-esteem a revolutionary approach to selfunderstanding that launched a new era in modern psychology. San Francisco, Calif: Jossey-Bass.

Brands, I., Kohler, S., Stapert, S., Wade, D., \& van Heugten, C. (2014). Influence of self-efficacy and coping on quality of life and social participation after acquired brain injury: A 1-year follow-up study. Arch Phys Med Rehabil, 95(12), 2327-2334. doi:10.1016/j.apmr.2014.06.006

Brinkmann, J.R., \& Hoskins, T.A. (1979). Physical conditioning and altered selfconcept in rehabilitated hemipelegic patients. Physical Therapy, 59(7), 859865.

Brooks, N., McKinlay, W., Symington, C., Beattie, A., \& Campsie, L. (1987). Return to work within the first seven years of severe head injury. Brain Injury, 1(1), $5-19$.

Brown, G.W., Andrews, B., Bifulco, A., \& Veiel, H. (1990). Self-esteem and depression. 1. Measurement issues and prediction of onset. Social Psychiatry and Psychiatric Epidemiology, 25(4), 200-209.

Bryant, R.A., Marosszeky, J.E., Crooks, J., \& Gurka, J.A. (2000). Posttraumatic stress disorder after severe traumatic brain injury. American Journal of Psychiatry, 157(4), 629-631.

Cantor, J.B., Ashman, T.A., Schwartz, M.E., Gordon, W.A., Hibbard, M.R., Brown, M., . . Cheng, Z. (2005). The role of self-discrepancy theory in understanding post-traumatic brain injury affective disorders: A pilot study. The Journal of Head Trauma Rehabilitation, 20(6), 527-543. 
Carroll, E., \& Coetzer, R. (2011). Identity, grief and self-awareness after traumatic brain injury. Neuropsychological Rehabilitation, 21(3), 289-305. doi:Pii 934339402

Cicerone, K.D., \& Azulay, J. (2007). Perceived self-efficacy and life satisfaction after traumatic brain injury. The Journal of Head Trauma Rehabilitation, 22(5), 257-266. doi: 10.1097/01.htr.0000290970.56130.81

Cicerone, K.D., Mott, T., Azulay, J., Sharlow-Galella, M.A., Ellmo, W.J., Paradise, S., \& Friel, J.C. (2008). A randomized controlled trial of holistic neuropsychologic rehabilitation after traumatic brain injury. Archives of Physical Medicine and Rehabilitation, 89(12), 2239-2249. doi:

10.1016/j.apmr.2008.06.017

Cohen, J. (1988). Statistical power analysis for the behavioural sciences. Hillsdale, N.J: L. Erlbaum Associates.

Cooper-Evans, S., Alderman, N., Knight, C., \& Oddy, M. (2008). Self-esteem as a predictor of psychological distress after severe acquired brain injury: An exploratory study. Neuropsychological Rehabilitation, 18(5-6), 607-626. doi: $10.1080 / 09602010801948516$

Curran, C.A., Ponsford, J.L., \& Crowe, S. (2000). Coping strategies and emotional outcome following traumatic brain injury: A comparison with orthopedic patients. Journal of Head Trauma Rehabilitation, 15(6), 1256-1274. doi: $10.1097 / 00001199-200012000-00006$

Daskalopoulou, E.G., Dikeos, D.G., Papadimitriou, G.N., Souery, D., Blairy, S., Massat, I., . . . Stefanis, C.N. (2002). Self-esteem, social adjustment and suicidality in affective disorders. European Psychiatry, 17(5), 265-271.

Dawkins, N., Cloherty, M.E., Gracey, F., \& Evans, J.J. (2006). The factor structure of 
the Hospital Anxiety and Depression Scale in acquired brain injury. Brain Injury, 20(12), 1235-1239. doi: V041611313646066 [pii\} 10.1080/02699050601076414

Dori, G.A., \& Overholser, J.C. (1999). Depression, hopelessness, and self-esteem: Accounting for suicidality in adolescent psychiatric inpatients. Suicideand Life Threatening Behavior, 29(4), 309-318.

Ellis-Hill, C.S., \& Horn, S. (2000). Change in identity and self-concept: A new theoretical approach to recovery following a stroke. Clinical Rehabilitation, 14(3), 279-287. doi: 10.1191/026921500671231410

Fann, J.R., Katon, W.J., Uomoto, J.M., \& Esselman, P.C. (1995). Psychiatric disorders and functional disability in outpatients with traumatic brain injuries. American Journal of Psychiatry, 152(10), 1493-1499.

Fennell, M.J. (1997). Low self-esteem: A cognitive perspective. Behavioural and Cognitive Psychotherapy, 25, 1-26. doi: 10.1017/S1352465800015368

Fennell, M. J. V. (1998). Low self-esteem. In Treating Complex Cases: The Cognitive-Behavioural Therapy Approach (eds N. Tarrier, A. Wells \& G. Haddock). Chichester: Wiley. p. 217-240.

Field, A. (2013). Discovering statistics using IBM SPSS statistics. London: Sage. p. $665-719$.

Fleminger, S., Oliver, D., Williams, W.H., \& Evans, J. (2003). The neuropsychiatry of depression after brain injury. Neuropsychological Rehabilitation, 13(1), 65-87. doi: 10.1080/09602010244000354.

Garske, G.G., \& Thomas, K.R. (1992). Self-reported self-esteem and depression: Indexes of psychosocial adjustment following severe traumatic brain injury. Rehabilitation Counseling Bulletin, 36(1), 44-52. 
Gracey, F., Evans, J.J., \& Malley, D. (2009). Capturing process and outcome in complex rehabilitation interventions: A "Y-shaped" model. Neuropsychological Rehabilitation, 19(6), 867-890. doi: $10.1080 / 09602010903027763$

Gracey, F., Palmer, S., Rous, B., Psaila, K., Shaw, K., O'Dell, J., . . Mohamed, S. (2008). "Feeling part of things": Personal construction of self after brain injury. Neuropsychological Rehabilitation, 18(5-6), 627-650. doi: $10.1080 / 09602010802041238$

Gracey, F., Ford, C., \& Psaila, K. (2015). A provisional transdiagnostic cognitive behavioural model of post brain injury emotional adjustment. . NeuroDisability and Psychotherapy, 3(2), 154-185.

Gray-Little, B., Williams, V.S.L., \& Hancock, T.D. (1997). An item response theory analysis of the Rosenberg self-esteem scale. Personality and Social Psychology Bulletin, 23(5), 443-451. doi: 10.1177/0146167297235001

Gutman, S.A., \& Napier-Klemic, J. (1996). The experience of head injury on the impairment of gender identity and gender role. American Journal of Occupational Therapy, 50(7), 535-544.

Hatcher, J., \& Hall, L.A. (2009). Psychometric properties of the rosenberg self-esteem scale in african american single mothers. Issues in Mental Health Nursing, 30(2), 70-77.

Hoofien, D., Barak, O., Vakil, E., \& Gilboa, A. (2005). Symptom checklist-90 revised scores in persons with traumatic brain injury: Affective reactions or neurobehavioural outcomes of the injury? Applied Neuropsychology, 12(1), 30-39.

Howes, H.F., Edwards, S., \& Benton, D. (2005a). Female body image following 
acquired brain injury. Brain Injury, 19(6), 403-415.

Howes, H.F., Edwards, S., \& Benton, D. (2005b). Male body image following acquired brain injury. Brain Injury, 19(2), 135-147. doi:

$10.1080 / 02699050410001720077$

Jones, J.M., Haslam, S.A., Jetten, J., Williams, W.H., Morris, R., \& Saroyan, S. (2011). That which doesn't kill us can make us stronger (and more satisfied with life): The contribution of personal and social changes to well-being after acquired brain injury. Psychology and Health, 26(3), 353-369. doi: 921519476 [pii]

$10.1080 / 08870440903440699$

Jorge, R.E., \& Starkstein, S.E. (2005). Pathophysiologic aspects of major depression following traumatic brain injury. The Journal of Head Trauma Rehabilitation, $20(6), 475-487$.

Keppel, C.C., \& Crowe, S.F. (2000). Changes to body image and self-esteem following stroke in young adults. Neuropsychological Rehabilitation, 10(1), 15-31. doi: 10.1080/096020100389273

Kinsella, G., Ford, B., \& Moran, C. (1989). Survival of social relationships following head injury. International Disability Studies, 11(1), 9-14.

Langlois, J.A., Rutland-Brown, W., \& Wald, M.M. (2006). The epidemiology and impact of traumatic brain injury: A brief overview. The Journal of Head Trauma Rehabilitation, 21(5), 375-378.

Lincoln, N.B., Kneebone, I.I., Macniven, J.A., \& Morris, R.C. (2011). Psychological Management of Stroke: Chichester: Wiley.

Malec, J. F., Brown, A. W., Leibson, C. L., Flaada, J. T., Mandrekar, J. N., Diehl, N. N., \& Perkins, P. K. (2007). The mayo classification system for traumatic 
brain injury severity. J Neurotrauma, 24(9), 1417-1424.

doi:10.1089/neu.2006.0245

Malec, J.F., Brown, A.W., Moessner, A.M., Stump, T.E., \& Monahan, P. (2010). A preliminary model for posttraumatic brain injury depression. Archives of Physical Medicine and Rehabilitation, 91(7), 1087-1097.

Mann, M., Hosman, C.M.H., Schaalma, H.P., \& de Vries, N.K. (2004). Self-esteem in a broad-spectrum approach for mental health promotion. Health Education Research, 19(4), 357-372.

McManus, F., Waite, P., \& Shafran, R. (2009). Cognitive-behavior therapy for low self-esteem: A case example. Cognitive and Behavioural Practice, 16(3), 266275. doi: http://dx.doi.org/10.1016/j.cbpra.2008.12.007

Nochi, M. (1998). "Loss of self" in the narratives of people with traumatic brain injuries: A qualitative analysis. Social Science \& Medicine, 46(7), 869-878. doi: 10.1016/s0277-9536(97)00211-6

Nochi, M. (2000). Reconstructing self-narratives in coping with traumatic brain injury. Social Science \& Medicine, 51(12), 1795-1804. doi: 10.1016/s02779536(00)00111-8

Norton, S., Cosco, T., Doyle, F., Done, J., \& Sacker, A. (2012). The hospital anxiety and depression scale: A meta confirmatory factor analysis. Journal of Psychosomatic Research, 74(1), 74-81. doi:10.1016/j.jpsychores.2012.10.010

Oddy, M., \& Herbert, C. (2003). Intervention with families following brain injury: Evidence-based practice. Neuropsychological Rehabilitation, 13(1), 259-273. doi:10.1080/09602010244000345

Olssøn, I., Mykletun, A., \& Dahl, A. (2005). The hospital anxiety and depression rating scale: A cross-sectional study of psychometrics and case finding 
abilities in general practice. BMC Psychiatry, 5(1), 46.

Rice, K.G., Ashby, J.S., \& Slaney, R.B. (1998). Self-esteem as a mediator between perfectionism and depression: A structural equations analysis. Journal of Counseling Psychology, 45(3), 304-314. doi: 10.1037/0022-0167.45.3.304

Riley, G.A., Brennan, A.J., \& Powell, T. (2004). Threat appraisal and avoidance after traumatic brain injury: Why and how often are activities avoided? Brain Injury, 18(9), 871-888. doi: 10.1080/02699050410001671829

Riley, G.A., Dennis, R.K., \& Powell, T. (2010). Evaluation of coping resources and self-esteem as moderators of the relationship between threat appraisals and avoidance of activities after traumatic brain injury. Neuropsychological Rehabilitation, 20(6), 869-882. doi: 10.1080/09602011.2010.503041

Robson, P. (1989). Development of a new self-report questionnaire to measure self esteem. Psychological Medicine, 19, 513-518. doi:

$10.1017 / \mathrm{S} 003329170001254 \mathrm{X}$

Robson, P. (2002) Factor analysis of Self-Concept Questionnaire. Unpublished data, personal communication 5 June 2009.

Rosenberg, M. (1965). Society and the adolescent self-image. Princeton, NJ: Princeton University Press.

Schonberger, M., \& Ponsford, J. (2010). The factor structure of the hospital anxiety and depression scale in individuals with traumatic brain injury. Psychiatry Research, 179(3), 342-349. doi: 10.1016/j.psychres.2009.07.003

Shields, C., et al. (2015). "A transdiagnostic investigation of emotional distress after traumatic brain injury." Neuropsychological Rehabilitation(ahead-of-print): 136. DOI: $10.1080 / 09602011.2015 .1037772$

Teasdale, T.W., \& Engberg, A.W. (2001). Suicide after traumatic brain injury: A 
population study. Journal of Neurology, Neurosurgery \& Psychiatry, 71(4), 436-440. doi: 10.1136/jnnp.71.4.436

Thom, T., Haase, N., Rosamond, W., Howard, V.J., Rumsfeld, J., Manolio, T., . . . Wolf, P. (2006). Heart disease and stroke statistics—2006 update: A report from the american heart association statistics committee and stroke statistics subcommittee. Circulation, 113(6), e85-e151. doi:

10.1161/circulationaha.105.171600

Tielemans, N. S., Schepers, V. P., Visser-Meily, J. M., Post, M. W., \& van Heugten, C. M. (2015). Associations of proactive coping and self-efficacy with psychosocial outcomes in individuals after stroke. Archives of Physical Medicine and Rehabilitation, 96(8), 1484-1491. doi:http://dx.doi.org/10.1016/j.apmr.2015.04.009

Trexler, L. (2000). Empirical support for neuropsychological rehabilitation. In A.-L. Christensen \& B. P. Uzzell (Eds.), International handbook of neuropsychological rehabilitation (pp. 137-150): Springer US.

Tyerman, A., \& Humphrey, M. (1984). Changes in self-concept following severe head injury. International Journal of Rehabilitation Research, 7(1), 11-23.

Vallerand, R.J., Pelletier, L.G., \& Gagné, F. (1991). On the multidimensional versus unidimensional perspectives of self-esteem: A test using the group-comparison approach. Social Behavior and Personality: an international journal, 19(2), 121-132.

van Reekum, R., Bolago, I., Finlayson, M.A., Garner, S., \& Links, P.S. (1996). Psychiatric disorders after traumatic brain injury. Brain Injury, 10(5), 319-327. Vickery, C.D. (2006). Assessment and correlates of self-esteem following stroke using a pictorial measure. Clinical Rehabilitation, 20(12), 1075-1084. 
Vickery, C.D., Gontkovsky, S.T., Wallace, J.J., \& Caroselli, J.S. (2006). Group psychotherapy focusing on self-concept change following acquired brain injury: A pilot investigation. Rehabilitation Psychology, 51(1), 30-35. doi: $10.1037 / 0090-5550.51 .1 .30$

Vickery, C.D., Sepehri, A., Evans, C.C., \& Jabeen, L.N. (2009). Self-esteem level and stability, admission functional status, and depressive symptoms in acute inpatient stroke rehabilitation. Rehabilitation Psychology, 54(4), 432-439.

Whelan-Goodinson, R., Ponsford, J., \& Schönberger, M. (2009). Validity of the hospital anxiety and depression scale to assess depression and anxiety following traumatic brain injury as compared with the structured clinical interview for dsm-iv. Journal of Affective Disorders, 114(1-3), 94-102. doi: 10.1016/j.jad.2008.06.007

Whyte, E.M., \& Mulsant, B.H. (2002). Post stroke depression: Epidemiology, pathophysiology, and biological treatment. Biological Psychiatry, 52(3), 253264.

Wilson, B.A., Gracey, F., Malley, D., Bateman, A. and Evans, J. J. . (2009). The oliver zangwill centre approach to neuropsychological rehabilitation. In B. A. Wilson, Gracey, F., Bateman, A. and Evans, J. J (Ed.), Neuropsychological Rehabilitation: Theory, models, therapy and outcome (pp. 47-67). Cambridge: Cambridge University Press.

Wood, R.L., \& Rutterford, N.A. (2006). Demographic and cognitive predictors of long-term psychosocial outcome following traumatic brain injury. Journal of the International Neuropsychological Society, 12(3), 350-358.

Wright, J.C., \& Telford, R. (1996). Psychological problems following minor head injury: A prospective study. The British Journal of Clinical Psychology, 35(3), 
$399-412$.

Yeates, G., Henwood, K., Gracey, F., \& Evans, J. (2007). Awareness of disability after acquired brain injury and the family context. Neuropsychological Rehabilitation, 17(2), 151-173. doi: 777126249 [pii]

\section{$10.1080 / 09602010600696423$}

Zigmond, A.S., \& Snaith, R.P. (1983). The hospital anxiety and depression scale. Acta Psychiatrica Scandinavica, 67(6), 361-370. doi: 10.1111/j.16000447.1983.tb09716.x 